\title{
In vivo study of conductive 3D printed PCL/MWCNTs scaffolds with electrical stimulation for bone tissue engineering
}

\author{
Edney P. e Silva ${ }^{1} \cdot$ Boyang Huang $^{2}$ (D) Júlia V. Helaehil ${ }^{1}(\mathbb{D})$ Paulo R. L. Nalesso ${ }^{1}$ (D) Leonardo Bagne ${ }^{1}$ (D) \\ Maraiara A. de Oliveira ${ }^{1}$. Gabriela C. C. Albiazetti ${ }^{1}$ - Ali Aldalbahi ${ }^{3}$ (i) $\cdot$ Mohamed El-Newehy $^{3}$ (ID $\cdot$ \\ Milton Santamaria-Jr ${ }^{1}$ (D) Fernanda A. S. Mendonça ${ }^{1}$ (D) Paulo Bártolo ${ }^{2}$ (i) - Guilherme F. Caetano ${ }^{1}$ (D)
}

Received: 25 September 2020 / Accepted: 20 November 2020 / Published online: 5 January 2021

(c) The Author(s) 2021

\begin{abstract}
Critical bone defects are considered one of the major clinical challenges in reconstructive bone surgery. The combination of 3D printed conductive scaffolds and exogenous electrical stimulation (ES) is a potential favorable approach for bone tissue repair. In this study, 3D conductive scaffolds made with biocompatible and biodegradable polycaprolactone (PCL) and multi-walled carbon nanotubes (MWCNTs) were produced using the extrusion-based additive manufacturing to treat large calvary bone defects in rats. Histology results show that the use of PCL/MWCNTs scaffolds and ES contributes to thicker and increased bone tissue formation within the bone defect. Angiogenesis and mineralization are also significantly promoted using high concentration of MWCNTs (3 wt $\%$ ) and ES. Moreover, scaffolds favor the tartrate-resistant acid phosphatase (TRAP) positive cell formation, while the addition of MWCNTs seems to inhibit the osteoclastogenesis but present limited effects on the osteoclast functionalities (receptor activator of nuclear factor $\kappa \beta$ ligand (RANKL) and osteoprotegerin (OPG) expressions). The use of ES promotes the osteoclastogenesis and RANKL expressions, showing a dominant effect in the bone remodeling process. These results indicate that the combination of 3D printed conductive PCL/MWCNTs scaffold and ES is a promising strategy to treat critical bone defects and provide a cue to establish an optimal protocol to use conductive scaffolds and ES for bone tissue engineering.
\end{abstract}

Keywords Additive manufacturing - Bone regeneration - Bone remodeling - Carbon nanotube $\cdot$ Conductive scaffolds . Electrical stimulation

\section{Introduction}

Edney P. e Silva, Boyang Huang have contributed equally.

Electronic supplementary material The online version of this article (https://doi.org/10.1007/s42242-020-00116-1) contains

supplementary material, which is available to authorized users.

Paulo Bártolo

paulojorge.dasilvabartolo@manchester.ac.uk

$\bowtie$ Guilherme F. Caetano

caetanogf@fho.edu.br

1 Postgraduate Program in Biomedical Sciences, University Center of Hermínio Ometto Foundation-FHO, Araras, Sao Paulo, Brazil

2 Department of Mechanical, Aerospace and Civil Engineering, School of Engineering, University of Manchester, Manchester M13 9PL, UK

3 King Abdullah Institute for Nanotechnology, King Saud University, Riyadh 11451, Saudi Arabia
Successful bone reconstruction requires osteoproduction, osteoinduction, osteoconduction and vascularization [1]. Current clinical strategies to treat bone defects including autografts, allografts and xenografts present several major limitations such as shortage of donations, potential transmission of disease, risk of rejection and immunogenicity issues [2]. Tissue engineering, in particular the scaffold-based strategy, is a promising approach for bone tissue regeneration which can overcome these limitations [3-5]. Furthermore, additive manufacturing techniques combined with active biomaterials have been recognized as an effective way to produce porous $3 \mathrm{D}$ bone scaffolds with predefined internal shape and morphology, allowing better control of pore size and distribution [4].

Healthy bone tissue has the ability to generate endogenous electrical signals that stimulate the repair process by activating voltage-controlled calcium channels in the plasma 
membrane [6, 7]. After bone loss, the endogenous signs are compromised and sharply decrease at the site of criticalsize defects [8]. Moreover, with the bone fracture healing, the decreased bioelectric potential at the defect site returns back to its normal level [9]. These findings suggest that bone regeneration can be achieved by repairing the bioelectrical environment. Therefore, the exogenous ES was proposed to stimulate and accelerate the regeneration process, compensating the lack of endogenous electrical signals from healthy bone tissue $[10,11]$. However, the large gap within the bone defect may hinder the transmission of electrical signals. In this case, the use of electrical conductive scaffolds may overcome this limitation enabling adequate electrical stimulus to the injured bone.

A wide range of materials has been investigated to produce conductive scaffolds. Metallic materials such as titanium and titanium alloys (Ti6Al4V) present high conductivity, but they are not biodegradable, and produced scaffolds present high mechanical strength compared with the surrounding tissue leading to stress shield and bone loss [12, 13]. Conductive polymers such as polypyrrole (PPy), polyaniline (PANi) and poly(3,4-ethylenedioxythiophene) (PEDOT) are also promising conductive material candidates to produce conductive scaffold [14]. These polymers are usually synthesized as a composite with non-conductive biocompatible and degradable polymers such as PCL [15], poly(D, L-lactide) (PDLLA) [16] and poly (L-lactic) acid (PLLA) [17]. However, challenges still remain for these polymers due to their manufacturing limitation (some of them cannot be melted), potential toxicity and poor solubility in solvents [18-20]. Inorganic conductive materials including graphene, carbon nanofibers and carbon nanotubes are also being investigated [21]. Among them, carbon nanotubes (CNTs) are particularly relevant due to their exceptional mechanical, electrical conductivity and their unique dimensional structure characteristics (one-dimensional and high aspect ratio material). The incorporation of CNTs into a polymer matrix displays a variety of structural and physiochemical reinforcement characteristics, including the improvement of strength, flexibility and biocompatibility, induction of angiogenesis, reduction of thrombosis and manipulation of gene expression for tissue repair [22]. Previously, our group investigated the use of PCL and multi-wall CNTs (MWCNTs) to produce bone scaffolds through additive manufacturing [23, 24]. Results showed that the use of a screw-assisted extrusion additive manufacturing system allowed to obtain a highly ordered arrangement of CNTs in an anisotropic manner within the polymer matrix, enabling to create a hierarchical porous structure. Produced PCL/MWCNTs scaffolds containing $0.75 \mathrm{wt} \%$ and $3 \mathrm{wt} \%$ of MWCNTs showed enhanced mechanical properties, non-toxicity and bone-related cell differentiation. Results showed that scaffolds containing 3 wt $\%$ of MWCNTs presented statistically higher com- pressive modulus $(\sim 84 \mathrm{MPa})$ compared with scaffolds containing $0.75 \mathrm{wt} \%$ of MWCNTs $(\sim 54 \mathrm{MPa})$ and PCL scaffolds ( 49 MPa) [23]. Moreover, scaffolds containing $3 \mathrm{wt} \%$ and $0.75 \mathrm{wt} \%$ of MWCNTs presented statistically higher surface hardness (both $0.05 \mathrm{GPa}$ ) and elastic modulus ( $0.65 \mathrm{GPa}$ and $0.60 \mathrm{GPa}$, respectively) than PCL scaffolds (surface hardness $0.04 \mathrm{GPa}$ and elastic modulus $0.49 \mathrm{GPa}$ ) [23]. There is no significant difference between the pore structure/shape and size (varying from $366 \mu \mathrm{m}$ to $397 \mu \mathrm{m}$ ) [23]. Moreover, polarized Raman results showed that the addition of $0.75 \mathrm{wt} \%$ of MWCNTs into the PCL matrix was well dispersed and aligned along the printing direction [24]. Based on the success of these preliminary results, this paper investigates the in vivo performance of PCL/MWCNTs scaffolds containing $0 \mathrm{wt} \%, 0.75 \mathrm{wt} \%$ and $3 \mathrm{wt} \%$ of MWCNTs as the conductive implants. As most in vivo studies focus on the relatively early-stage of bone formation (approximately 2 months) [25-28], this paper also investigates the effect of conductive scaffolds combined with ES on the late-stage of bone formation, particularly the bone remodeling process reaching homeostasis that remains unknown.

\section{Experimental methods}

\section{Scaffold fabrication}

Two concentrations of MWCNTs $(0.75 \mathrm{wt} \%$ and $3 \mathrm{wt} \%$, respectively) were considered to produce the PCL/MWCNTs conductive scaffolds. Briefly, PCL pellets were heated at $90{ }^{\circ} \mathrm{C}$ for 20 min followed by the addition of MWCNTs. The composite materials were thoroughly mixed for $30 \mathrm{~min}$ to ensure homogeneous dispersion. 3D porous scaffolds with $0 / 90^{\circ}$ laydown pattern were fabricated using a screw-assisted extrusion-based additive manufacturing system (3D Discovery, RegenHU, Villaz-Saint-Pierre, Switzerland) considering the following processing conditions: melting temperature of $90{ }^{\circ} \mathrm{C}$, air pressure of 6 bar, screw-rotational velocity of $12 \mathrm{rpm}$ and the deposition velocity of $20 \mathrm{~mm} / \mathrm{s}$. Nonconductive PCL scaffold was also produced and used as a reference. The dimensions of the printed scaffolds were $30 \mathrm{~mm} \times 30 \mathrm{~mm} \times 2.5 \mathrm{~mm}$ and cut to fit the bone defect in the animal models $(5 \mathrm{~mm} \times 5 \mathrm{~mm} \times 2.5 \mathrm{~mm})$, sterilized in $70 \%$ ethanol for $4 \mathrm{~h}$ and rinsed in sterile saline solution to remove the residual ethanol. The images of printed scaffolds are shown in Fig. 1.

\section{In vitro study}

In order to obtain the optimal ES conditions, around $1 \times$ $10^{4}$ UMR-106 cells (rat osteoblasts-ATCC $® C R L-1661^{\mathrm{TM}}$ ) in $1 \mathrm{~mL}$ of culture medium (DMEM with high glucose, $10 \%$ fetal bovine serum) were seeded in 24-well plates and divided 


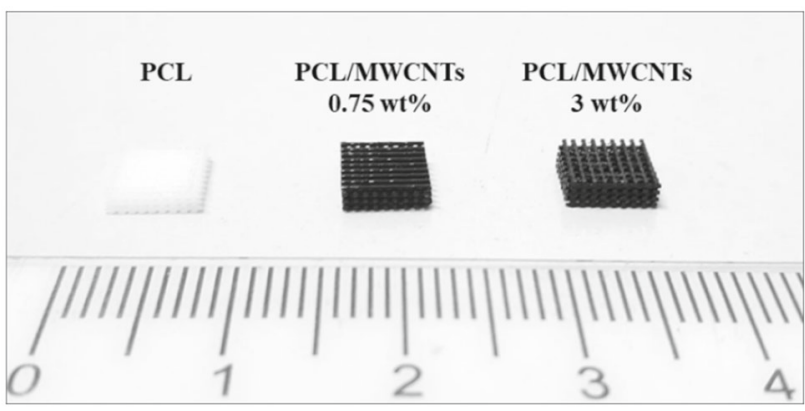

Fig. 1 Images of 3D printed scaffolds before the implantation

according to the ES period application: $0 \mathrm{~s}, 60 \mathrm{~s}, 150 \mathrm{~s}$ and $300 \mathrm{~s}$. As this was a short-term study, ES was performed three times per week for 9 days by placing two metal electrodes coupled to a low-intensity transcutaneous electrical stimulator (micro-galvanic direct current stimulation) (Physiotonus Microcurrent, BIOSET®, Indústria de Tecnologia Eletrônica Ltda. Rio Claro, SP, Brazil) considering an intensity of $10 \mu \mathrm{A}$ applied to the well covered with culture medium. The mitochondrial activity of osteoblasts was determined using the MTT colorimetric assay (SIGMA, USA) to assess cell viability for up to 7 days (plate reader at $540 \mathrm{~nm}$ ). In addition, osteoblasts were cultured in an osteogenic medium $(200 \mu \mathrm{M}$ ascorbic acid, $10 \mathrm{mM} \beta$-glycerophosphate and $0.5 \mu \mathrm{M}$ dexamethasone, SIGMA, USA) by applying ES to assess the mineralization of the extracellular matrix until day 9. The calcium deposition was quantified by staining the cell matrix with alizarin red S (SIGMA, USA) followed by the addition of $10 \%$ acetic acid and read in a $450 \mathrm{~nm}$ plate reader.

\section{In vivo study}

\section{Animals}

A total of 96 male Wistar rats (weight approximately $450 \mathrm{~g}$, age 6 months) were considered and obtained from the Animal Experiment Center at the University Center of Hermínio Ometto Foundation (Brazil) and randomly divided into eight experimental groups $(n=12)$ as listed in Table 1. Each group comprises 12 rats. Two experimental periods were considered (60 days and 120 days) for the analysis, and the rats were equally divided ( $n=6 /$ group/period).

All surgical and experimental procedures were performed according to the experimental standards and biodiversity rights (NIH Publication 80-23, revised 1996 and Arouca Law-11, 794, 2008), approved by ethical principles in animal research adopted by COBEA and the Hermínio Ometto Foundation's Ethics Committee on animal use (CEUA/UNIARARAS, 002/2018). All animals were healthy during the entire study, and the experimental procedure did not promote any stress.

\section{Surgical protocol}

All animals were anesthetized by the intraperitoneal administration of a mixture of ketamine hydrochloride $(30 \mathrm{mg} / \mathrm{kg})$ and xylazine hydrochloride $(10 \mathrm{mg} / \mathrm{kg})$. The trichotomy was performed in the occipital region of all animals, and a critical defect was created in the calvary bone (right parietal bone) by using an osteo I tip (PiezoHelse, Helse Dental technology, Santa Rosa de Viterbo, SP, Brazil), coupled with a dental ultrasound handpiece (Olsen, The Piezo Light D5 LED, Palhoça, SC, Brazil). A critical defect with dimensions of $5 \mathrm{~mm} \times 5 \mathrm{~mm} \times 2.5 \mathrm{~mm}$ was created under a constant saline irrigation, and the dura mater was preserved. The sterilized scaffolds were cut, fitting exactly to the defect without the need of any additional clamping or physical fixation. After the scaffold implantation, wounds were sutured with nylon 5-0 sutures (Johnson and Johnson, Brazil), followed by intraperitoneal and oral analgesic treatments using tramadol hydrochloride $(1 \mathrm{mg} / \mathrm{kg})$ and dipyrone $(50 \mathrm{mg} / \mathrm{kg})$, respectively, for 3 days.

\section{Electrical stimulation and post-treatment}

According to the results obtained from the in vitro study and following our previous in vivo protocol, ES was performed using a low intensity transcutaneous electrical stimulator
Table 1 Characteristics of different sample types

\begin{tabular}{lllll}
\hline Number & Group name & Scaffold implanted & Electrical stimulation & $\begin{array}{l}\text { MWCNTs concentration } \\
(\text { wt } \%)\end{array}$ \\
\hline 1 & Untreated & No* & No & 0 \\
2 & ES & No* & Yes & 0 \\
3 & PCL & Yes & No & 0 \\
4 & PCL/ES & Yes & Yes & 0 \\
5 & CNT0.75 & Yes & No & 0.75 \\
6 & CNT0.75/ES & Yes & Yes & 0.75 \\
7 & CNT3 & Yes & No & 3 \\
8 & CNT3/ES & Yes & Yes & 3 \\
\hline
\end{tabular}

* Indicates the natural bone formation 
Fig. 2 Schematic representation of the experimental setup
Screw-assisted

Additive

Manufacturing

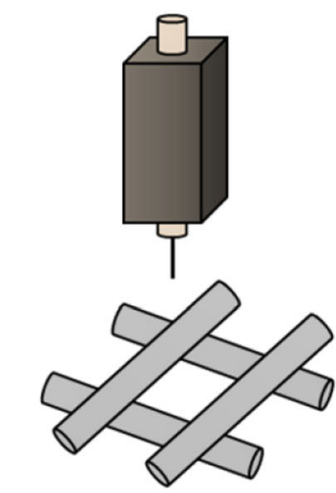

3D printed conductive

PCL/MWCNTs scaffold with

dimensions of

$30 \mathrm{~mm} \times 30 \mathrm{~mm} \times 2.5 \mathrm{~mm}$
Implanted

conductive scaffold

with dimensions of

$5 \mathrm{~mm} \times 5 \mathrm{~mm} \times 2.5 \mathrm{~mm}$

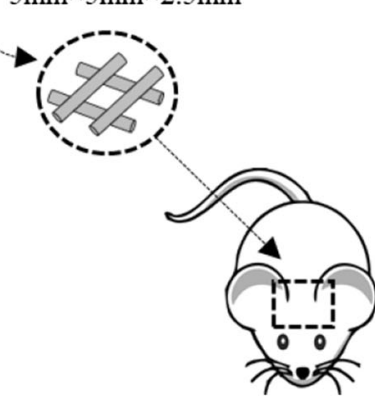

Intensity: $10 \mu \mathrm{A}$

ES durtation: 0s, 60s, 150 s and 300 s

Frequency: 3 times/per week

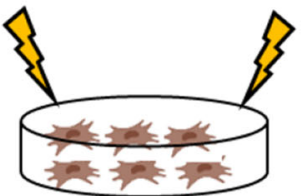

[29]. Two metal electrodes (10 mm diameter) were applied around the bone defect, but not fixed on the skull (a researcher handled the electrodes and kept them in contact with the animal, with the stimulated current being applied on the skull area), for $5 \mathrm{~min}$ at $10 \mu \mathrm{A}$ intensity twice a week (every Tuesdays and Fridays) throughout the experimental periods. For the in vivo studies and particularly considering future clinical trials, it was decided to reduce the frequency of the ES from three times a week as in the in vitro study to two times a week. This frequency is also less stressful to the animals and more convenient for potential long-treatment patients. The animals were euthanized after 60 days and 120 days of surgical procedure using both anesthetic deepening and cervical dislocation before bone sample collection. Samples were immediately fixed in $10 \%$ formaldehyde for $48 \mathrm{~h}$ for histomorphometric and immunohistochemical $(n=3)$ analysis, while the rest of the samples were immediately frozen at $-80{ }^{\circ} \mathrm{C}$ for molecular evaluations $(n=3)$ at days 60 and 120. The scaffold fabrication and both the in vitro and in vivo ES process are shown in Fig. 2.

\section{Histomorphometry}

After immersed in a fixative buffer containing $10 \%$ formaldehyde for $48 \mathrm{~h}$ at room temperature, bone samples were treated with $50 \%$ buffered formic acid decalcifying solution (Morse's decalcifying), with the solution being changed three times a week. After 30 days of treatment, the bone samples were washed in deionized water, dehydrated, embedded in paraffin, $4.0 \mu \mathrm{m}$ thick cross-sectioned, mounted on glass slides, stained with hematoxylin-eosin and Masson's Trichrome.

Histological images were captured using the Leica DM2000 microscope (Leica Microsystems, Germany), in a bright field mode at different magnifications and analyzed using the ImageJ software. After defining the total area of each image, the area of the scaffold filaments was subtracted to obtain the new tissue area (osteoid/collagen and/or mineralized tissue areas).

\section{Immunohistochemistry}

Samples were incubated with primary antibodies (Anti-OPG, Anti-RANKL, 1: 200; Santa Cruz Biotechnology, Dallas, USA). The secondary antibodies and detection reaction antibody (Novolink ${ }^{\mathrm{TM}}$ Max Polymer Detection System) were performed following the manufacturer's recommended protocol (Leica Biosystems, USA). TRAP kit (SIGMA, USA) was used according to the manufacturer's instructions. The RANKL, OPG and TRAP positive cells were quantified using ImageJ software.

\section{Extraction of bone proteins}

Around $200 \mathrm{mg}$ of bone tissue samples was collected and pulverized with the addition of liquid nitrogen and kept in buffer (50 mM sodium acetate, $\mathrm{pH}=5.8 ; 4 \mathrm{M}$ guanidine), at $4{ }^{\circ} \mathrm{C} / 24 \mathrm{~h}$. After centrifuging $\left(10,000 \mathrm{rpm} / 30 \mathrm{~min} / 4{ }^{\circ} \mathrm{C}\right)$, the supernatant was collected and treated with $10 \%$ ethanol at $4{ }^{\circ} \mathrm{C}$. The precipitated proteins were aliquoted and treated with protein blotting buffer for western blotting (Trisma base 
100 mM pH7,5; EDTA 10 mM; SDS 10\%; 100 mM sodium fluoride, $10 \mathrm{mM}$ sodium pyrophosphate, $10 \mathrm{mM}$ sodium orthovanadate). Collagen type I (COL-I, Santa Cruz Biotechnology, USA), bone morphogenetic protein-7 (BMP-7, Santa Cruz Biotechnology, USA) and GAPDH (housekeeping protein, Santa Cruz Biotechnology, USA) were measured. The intensity of the bands was evaluated using the ImageJ software.

\section{Statistical analysis}

For all experiments, the statistical analysis was performed using ANOVA two-way test and Bonferroni posttest using the GraphPad Prism software (Graphpad Software Inc., San Diego, CA, USA). The differences were considered significant with $p<0.05$.

\section{Results}

\section{In vitro study}

In order to find the optimal ES conditions, an in vitro study was performed and UMR-106 osteoblasts were cultured applying ES at different application times (Fig. 3). As observed from Fig. 3a, results show that cell viability increases with time and there is no significant difference between cells cultured with and without ES. This indicates that the selected micro-current intensity and the considered application times (up to $300 \mathrm{~s}$ ) are not harmful to the cells, but also seem to not significantly determine cell growth. However, as shown in Fig. 3b, the calcium deposition from the osteoblasts increases by increasing the ES application time, indicating that the use of ES might stimulate the secretion of bone matrix. This is particularly significant at day 9 as shown in Fig. 3c.

\section{In vivo study}

\section{Histomorphometry}

The bone defect created in the animal model is shown in Fig. 4a, and the implanted scaffold is shown in Fig. 4b. Calvary bone samples for all groups were collected after 60 days and 120 days after surgery as shown in Fig. 4c, d. The cross section histological images of the entire bone defects for all groups are shown in Fig. 4e. It is possible to observe that all groups present tissue bridging across the bone defects. However, the groups containing scaffolds show thicker tissue formations compared with the groups without scaffolds. Moreover, results seem to indicate that more connective and denser bone tissue is formed within the scaffolds containing MWCNTs submitted to ES. Figure $4 \mathrm{f}-\mathrm{m}$ presents the histo- logical images of all groups with the ES after 60 days. From Fig. 4f, g, it is possible to observe the formation of connective bone tissue within the bone defect. However, it is difficult to observe the apparent blood vessel formations and the mineralized bone tissue. Blood vessels formation can be observed in the PCL groups (Fig. 4h, i), but the mineralization process is still limited. An increase in mineralized bone tissue, with embedded osteocytes, is observed in the samples containing $0.75 \mathrm{wt} \%$ MWCNTs and $3 \mathrm{wt} \%$ MWCNTs. Moreover, the mineralized bone tissue also increases by increasing the concentration of MWCNTs (Fig. $4 \mathrm{j}-\mathrm{m}$ ). These results indicate that conductive PCL/MWCNTs scaffolds with ES are able to promote and accelerate the bone healing process. The histological analysis of all groups without ES after 60 days and all groups after 120 days presents similar results as shown in the supplementary information (Figure S1).

\section{Angiogenesis}

The quantification of angiogenesis for all considered groups is shown in Fig. 5a. Results show a high number of blood vessels in all scaffold groups in comparison with the natural bone formation groups (with and without ES). It can be also observed that the scaffold groups with ES (PCL/ES, CNT0.75/ES and CNT3/ES) present higher numbers of blood vessels than the scaffold groups without ES (PCL, CNT0.75 and CNT3) at day 60. However, no statistical difference is observed between them, suggesting that the use of ES might not be the unique factor for the angiogenesis. However, it is possible to observe that the number of blood vessels statistically increases with the addition of MWCNTs in comparison with natural bone formation groups and PCL group, which might be attributed to the improved electrical conductivity of the scaffolds and better electrical signal transmission. Moreover, results seem to indicate that the combination of both conductive scaffolds and ES has a synergistic effect on angiogenesis. Similar trend is also observed after 120 days of operation. However, the number of blood vessels decreases for all groups in comparison with the results obtained after 60 days, which might be due to the formation of more mineralized bone tissue.

\section{Connective and mineralized tissue}

Newly formed bone comprises connective and mineralized tissue. As shown in Fig. 5b, the CNT3/ES group shows a statistically high COL-1 expression at day 60 than the other considered groups, but no statistical difference is observed between the groups with and without ES. Between day 60 and day 120, COL-1 expression increases in the ES, PCL/ES and CNT3 groups but decreases in the other groups. This can be attributed to the bone remodeling process and to the fact that due to bone resorption process, COL-1 is degraded. 
(a)

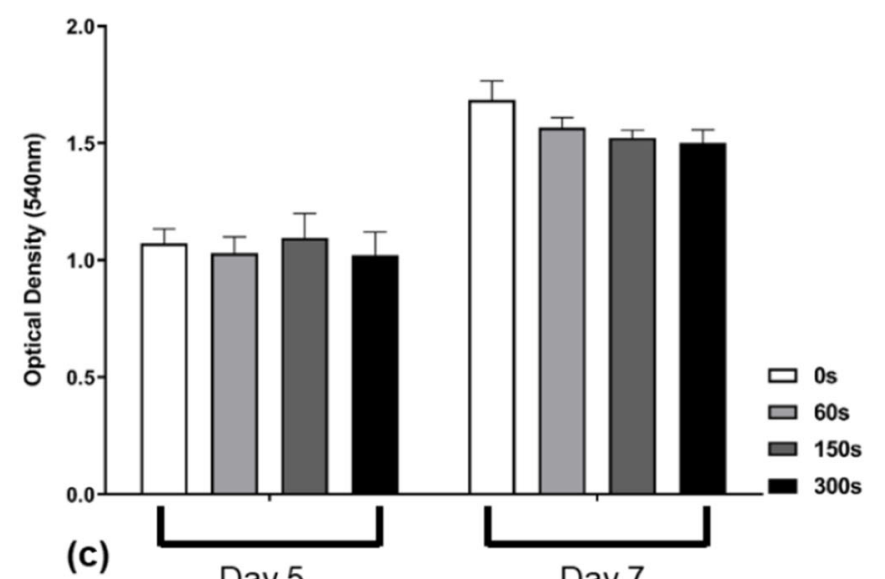

(c)

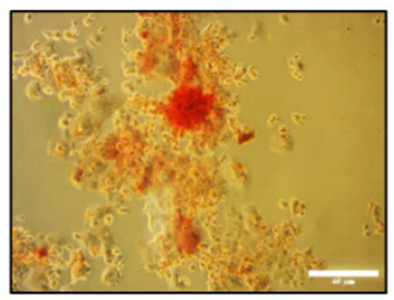

Os

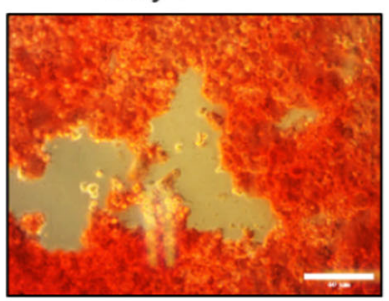

$60 \mathrm{~s}$

Fig. 3 In vitro analysis. a Cell viability at day 5 and 7 with different ES application times; b Calcium deposition produced by UMR-106 osteoblasts with different ES application times at day 5,7 and 9; c ARS

Similar results are observed for BMP-7 expression (Fig. 4c), with the CNT3/ES group presenting the highest value at day 60 . However, at day 120 , there is no statical difference in terms of BMP-7 expression among the different considered groups.

Results from Fig. 5d, e show that the new bone tissue is formed within the bone defect area after day 60 and the majority of newly formed tissue is in the form of connective tissue. According to the results, the PCL group shows a statistically high connective tissue compared with the ES group. Although there is an increasing trend of the connective tissue formation with the increase in MWCNTs concentration and the use of electrical stimulation, there is no significant difference between the groups with and without ES except for the PCL group and natural bone group with ES. Moreover, at day 60 , the scaffold groups exhibit high levels of mineralized tissue, indicating that the scaffolds are able to promote the bone mineralization process. Results also show that the mineralization process increases by increasing the concentration of MWCNTs. Likewise, PCL/ES, CNT0.75/ES and CNT3/ES groups show higher mineralized bone tissue in comparison with PCL, CNT0.75, CNT3 groups and statistically higher than natural bone formation groups (with and without ES), indicating that the use of ES is beneficial for the formation

(b)

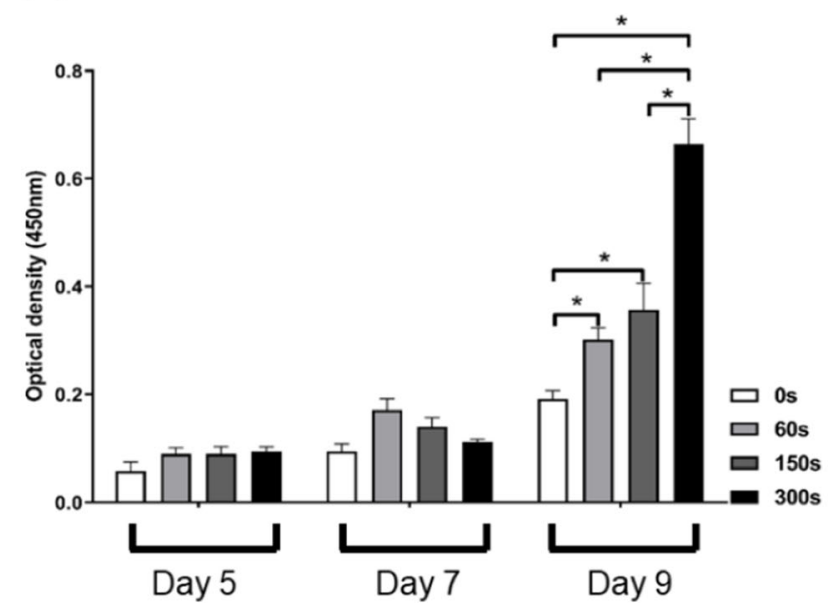

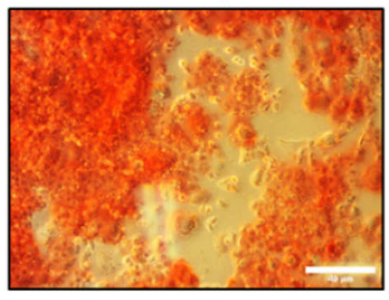

$150 \mathrm{~s}$

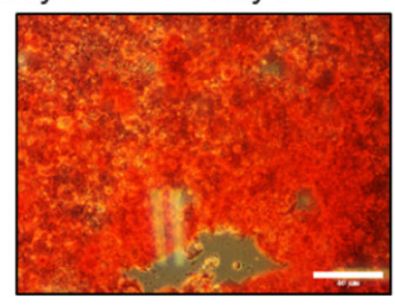

300 s staining images showing the calcium deposition with different ES times at day $9 ; *(P<0.05)$ represents statistical difference

of mature bone. At day 120, the level of connective bone tissue slightly decreases for all groups, while the mineralized bone tissue slightly increases in comparison with the groups at day 60 , indicating a transition from a fibrous tissue to a mature hard bone tissue. It is also possible to observe that by increasing the MWCNTs' concentration, the percentage of connective tissue decreases while the mineralized tissue increases, implying that the addition of MWCNTs promotes the transition of mature bone tissues from fibrous tissues. There is no obvious trend for the groups using electrical stimulation.

\section{Tissue remodeling}

In order to investigate the effects of conductive scaffolds and the ES on the bone remodeling process, TRAP positive cells (osteoclast), anti-RANKL and anti-OPG assays were performed. From Fig. 6a, it is possible to observe that the implanted scaffolds contribute to the recruitment of TRAP positive cells at day 60 . This might be attributed to the rigid surface of the scaffold that provides support for cell attachment and proliferation. TRAP positive cells slightly decrease in the scaffolds containing $3 \mathrm{wt} \%$ of MWCNTs. No significant differences are observed between PCL and conductive 

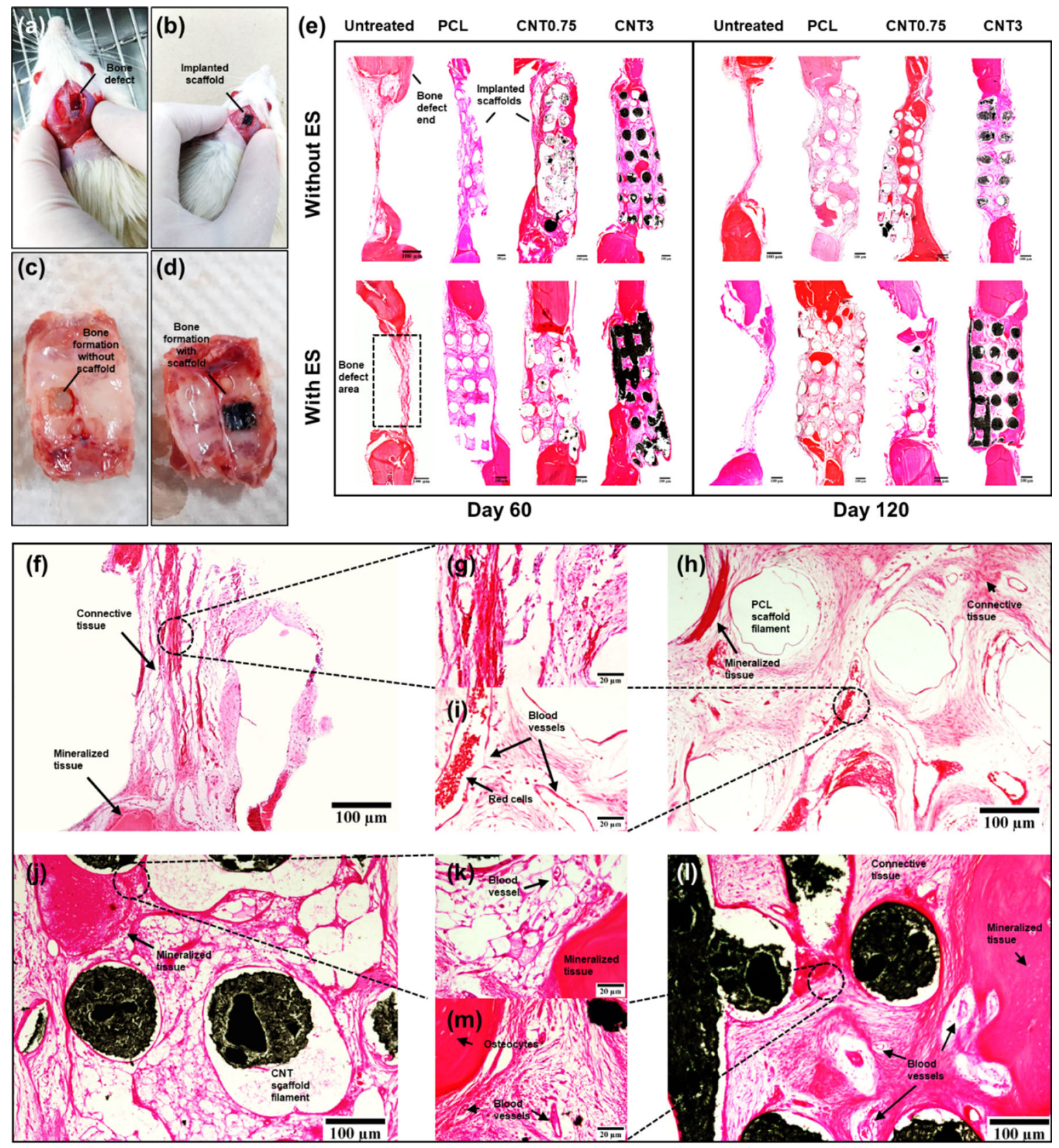

Fig. 4 Histomorphometry analysis a created bone defect in the animal model; $\mathbf{b}$ implanted scaffold at the bone defect; $\mathbf{c}$ bone tissue formation without scaffold after 60 days $\mathbf{d}$ bone tissue formation with a conductive scaffold after 60 days; $\mathbf{e}$ the cross sections of bone tissue regeneration at the bone defect for all groups after 60 days and 120 days; $\mathbf{f}$ the natural bone tissue regeneration with ES after 60 days; $\mathbf{g}$ higher magnification image of the natural bone tissue regeneration with ES after 60 days; h bone formation in the PCL scaffold group with ES after 60 days; i higher magnification image of the bone formation in the PCL scaffold group with ES after 60 days; $\mathbf{j}$ bone formation in the PCL/MWCNTs $0.75 \mathrm{wt} \%$ scaffold group with ES after 60 days; $\mathbf{k}$ higher magnification image of the bone formation in the PCL/MWCNTs $0.75 \mathrm{wt} \%$ scaffold group with ES after 60 days; 1 bone formation in the PCL/MWCNTs $3 \mathrm{wt} \%$ scaffold group with ES after 60 days; $\mathbf{m}$ higher magnification image of the bone formation in the PCL/MWCNTs $3 \mathrm{wt} \%$ scaffold group with ES after 60 days
PCL/MWCNTs scaffolds considering both ES and non-ES groups. Moreover, as shown in Fig. 6b, c, after 60 days, there are no statistical differences between all groups regarding both RANKL and OPG expression, indicating that the implanted scaffolds and ES have a limited effect on the func- tionality of osteoclasts. After day 120, the number of TRAP positive cells slightly decreases for all groups. However, the levels of RANKL and OPG are highly expressed at day 120, showing that more osteoclasts are activated. No statistical differences are observed in terms of both the number of TRAP 


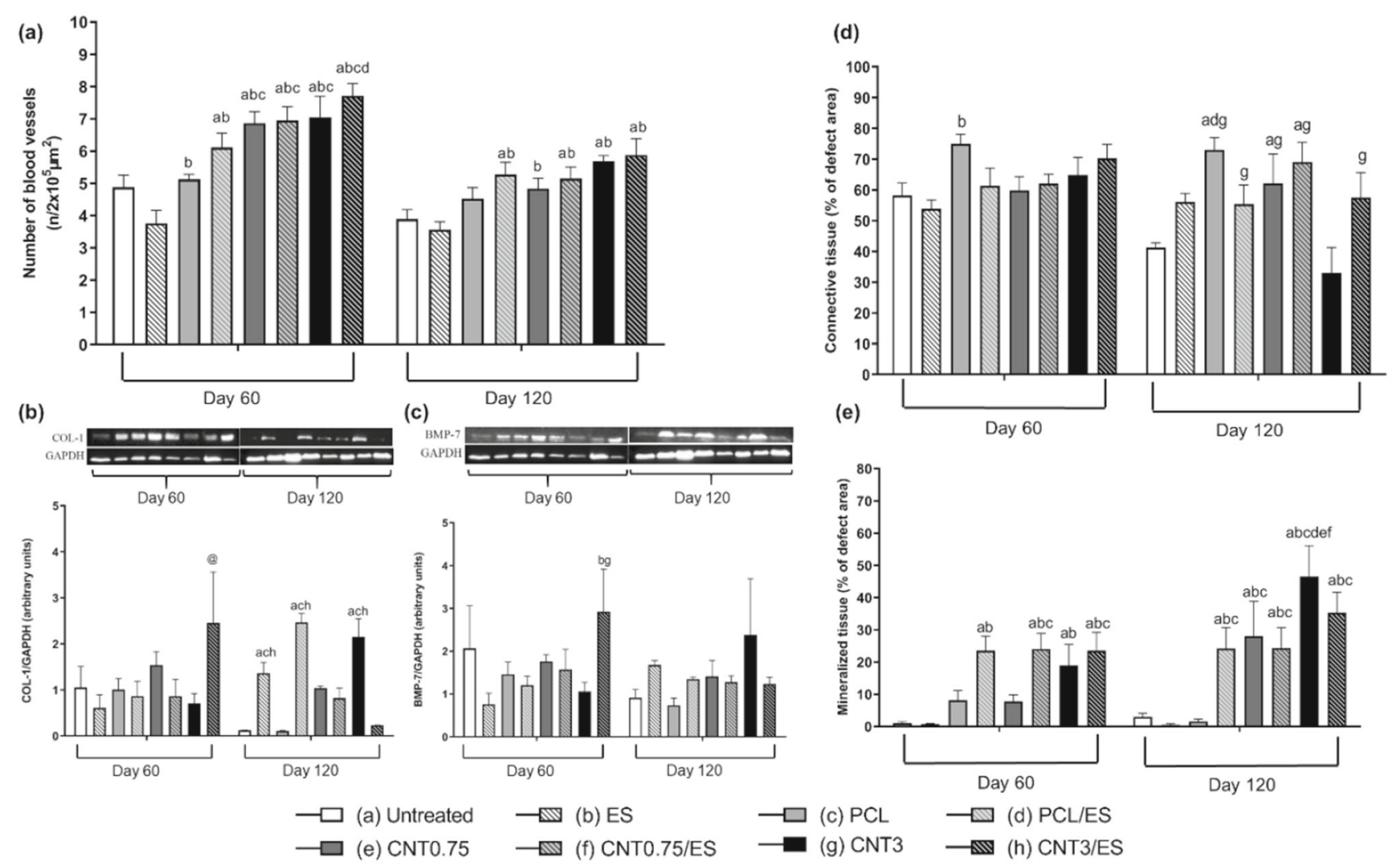

Fig. 5 Histological quantification analysis a number of blood vessels present in a $2 \times 10^{5} \mu^{2}$ area of the bone defect; b western blotting results of COL-1 protein expression and their semi-quantification; c western blotting results of BMP-7 protein expression and their semi-quantification; $\mathbf{d}$ connective tissue formed in the bone defect; e mineralized tissue formed in the bone defect for all groups after 60 days and 120; data were demonstrated by means/standard error and submitted to the two-way ANOVA test and Bonferroni posttest $(p<0.05)$. Group names are represented by different letters and column patterns. Letters above the bars mean statistical difference. @ means statistical difference compared with rest of the groups

terials allowing to produce, in a precise and reproducible way, 3D porous, biodegradable and biocompatible scaffolds, which are able to respond to external electrical stimuli and to accelerate the bone healing process.

Previous studies focused on the use of conductive scaffold with and without ES. Anne et al. [30] reported the fabrication of 3D poly(3,4-ethylenedioxythiophene) polystyrene sulfonate (PEDOT:PSS) conductive scaffolds using the freeze-drying method. In vitro studies without ES showed that the produced scaffolds induced the differentiation of osteogenic precursor cells (MC3T3-E1) into osteocalcin positively stained osteoblasts and the gene expression of osteogenic markers were significantly enhanced. Similarly, Chen et al. [31] produced polylactide (PLA)/PANi using thermal-induced phase separation and investigated the osteogenic behavior without ES. The results showed that conductive scaffolds increased osteogenic marker expressions of bone marrow-derived mesenchymal stem cells (BMSCs). Our group also found that the use of PCL/MWCNTs and PCL/MWCNTs/HA scaffolds without ES is able to promote cell attachment, proliferation and differentiation of human
The use of bioactive scaffolds is fundamental in tissue engineering to treat large bone defects. It is particularly relevant to combine additive manufacturing and conductive bioma- 
(a)

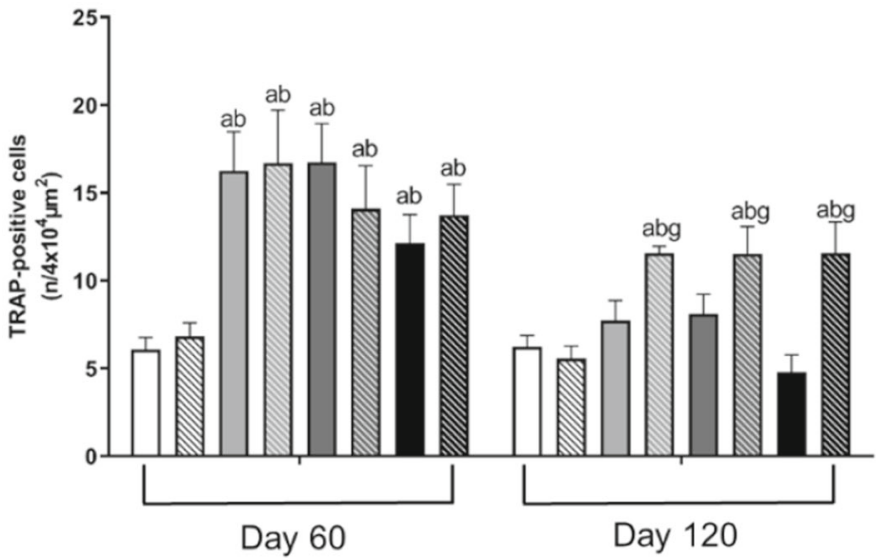

(b)

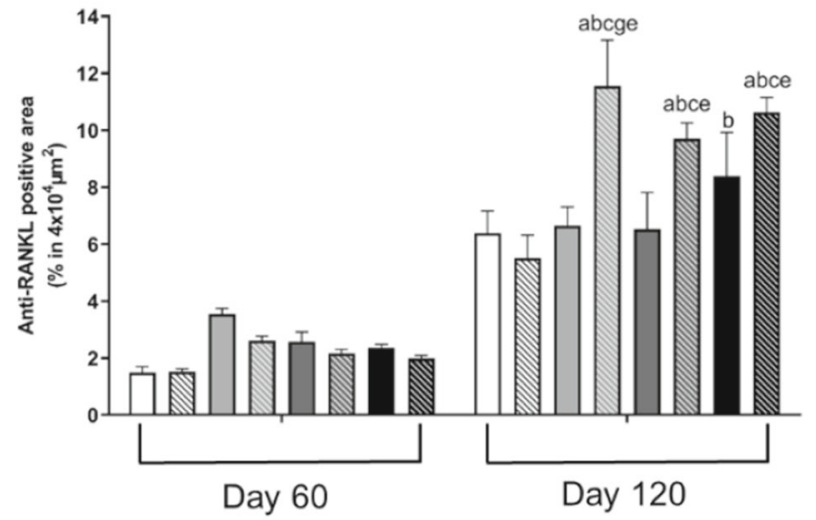

(c)

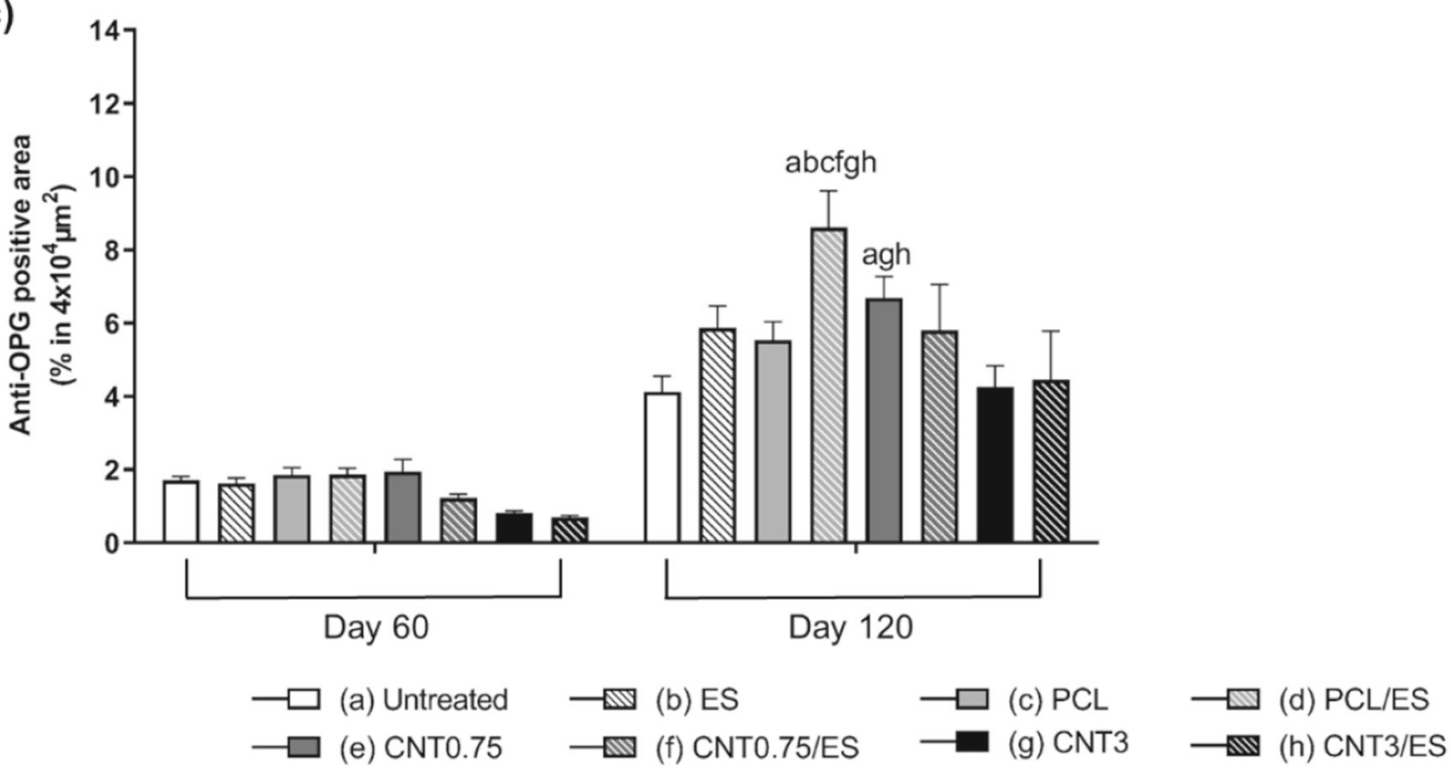

Fig. 6 Immunohistochemistry analysis a quantification of TRAP positive cells present in a $4 \times 10^{4} \mu \mathrm{m}^{2}$ area of bone defect; $\mathbf{b}$ percentage of positive anti-RANKL expression present in a $4 \times 10^{4} \mu \mathrm{m}^{2}$ area of bone defect; $\mathbf{c}$ percentage of positive anti-OPG expression present in a $4 \times 10^{4}$

adipose-derived stem cells (hADSCs) [23, 24]. These might be attributed to the ability of conductive scaffolds to transmit the endogenous electrical signals capable of promoting the cell-cell and cell-material interactions and strengthening the sense on cells toward the microenvironment. Moreover, the use of ES can further strengthens this behavior. Huang et al. [32] investigated the behavior of silicone scaffolds with and without ES and found a significant increase in osteogenic protein expressions in the groups treated with ES compared with non-treated groups. Similar findings were also reported by Bikendra et al. [33] using PCL/polypyrrole (PPy) scaffolds showing better MC3T3-E1cell adhesion, proliferation and differentiation when used together with ES. $\mu \mathrm{m}^{2}$ area of bone defect. Data were demonstrated by means/standard error and submitted to the two-way ANOVA test and Bonferroni posttest $(p<0.05)$. Group names are represented by different letters and column patterns. Letters above the bars mean statistical difference

However, the mechanism of how ES modulates the cellular behavior still remains unknown due to the variety of related factors such as the activation of the ion fluxes through the voltage-gated ion channels, membrane potential redistribution and conformational transition of proteins [34, 35]. The ES processing parameters (intensity and application time) might also influence the cellular behavior, and the corresponding values must be adjusted depending on the cell lines $[34,36]$. Different in vivo and in vitro studies suggested that current intensities between $10 \mu \mathrm{A}$ and $50 \mu \mathrm{A}$ can stimulate tissue repair, while intensities above $50 \mu \mathrm{A}$ can induce cell death [37]. In this study, in vitro results, considering a current intensity of $10 \mu \mathrm{A}$ applied for $5 \mathrm{~min}$ three times a week, showed good cell viability and enhanced the calcium deposi- 
tion produced by osteoblasts, indicating that this is a proper protocol for the in vivo study.

Vascularization plays an important role in bone development, remodeling and homeostasis [38, 39]. This study shows that PCL/MWCNTs conductive scaffolds and ES promote angiogenesis. This can be attributed to the fact that ES triggers cells to produce vascular endothelial growth factor (VEGF) proteins enhancing angiogenesis [11, 40, 41]. Results also show no statistical differences between the untreated group and the ES group without scaffold while the number of blood vessel significantly increases by using scaffolds. It can be assumed that the presence of a scaffold contributes to the rapid recruitment of angiogenesisrelated cells, providing a solid and rigid surface to allow cell attachment, proliferation and differentiation. The addition of MWCNTs and the use of ES can further strengthen this behavior presenting synergistic effects that enable angiogenesis.

Biosafety issues of CNTs are still debatable, and the cytotoxicity is considered to be induced when they are internalized and accumulated in the cells [42]. However, Mukherjee et al. [43] reported no signs of inflammation and toxicological effects on the kidney and liver of rabbits using hydroxyapatite (HA)/CNTs after 120 days. Previously, we also reported the in vitro use of PCL/MWCNTs and PCL/HA/MWCNTs and no cytotoxicity effects on hADSCs were observed $[23,24]$. We attribute it to the low concentration of CNTs and the encapsulated CNTs in the polymer matrix, reducing the risk of cellular uptake. The results presented in this paper show that the addition of MWCNTs improves the conductivity of PCL scaffolds (supplementary information S2), enhancing bone formation. Results show that the addition of MWCNTs has limited effects on the connective tissue formation but significantly promotes the mineralized tissue formation, which is distributed around the printed filaments (Fig. 4 and supplementary information S1). These could be attributed to multiple reasons. The use of CNTs enables modulating the cellular behavior through ES, leading to osteogenic differentiation [44]. Moreover, the MWCNTs on the filament surface act as nucleating sites allowing the deposition of an apatite layer produced by the osteogenic cells [45] and a mineral layer that further promotes the osteogenic differentiation [46].

Bone growth and remodeling associated with bone homeostasis are concurrently occurred physiological events in the whole process of bone tissue regeneration, in which osteoblasts synthesize new bone tissues and osteoclasts are responsible for resorption of existing bone. Pathological increase in bone resorption is triggered when osteoclasts have their activity rate increased and the RANKL and OPG proteins relationship reflects the bone remodeling environment $[47,48]$. Therefore, it is important to investigate the effects of conductive scaffolds and ES on the osteoclastogenesis behav- ior. Previously, it was reported that the osteoclastogenesis is sensitive to the microenvironment and could be modulated by the surface properties [49], scaffold topology and bone-related proteins [50], overexpression of VEGFs [51], local ionic concentration [52] and $\mathrm{pH}$ values of biomaterial microenvironment [53]. To the author's best knowledge, few studies investigated the effects of conductive scaffolds and, in particular, the use of ES on the osteoclast formation and functions. In this study, it is possible to observe that a larger number of osteoclasts were recruited by the scaffolds at day 60 compared with those at day 120 . However, the low expression of RANKL and OPG indicates that the osteoclasts present lower activities at day 60 compared with day 120. It is also possible to observe that the scaffolds containing MWCNTs present a decreasing trend of osteoclast cell density at the two considered time points (day 60 and day 120), suggesting the inhibition of osteoclast formation. This is in agreement with Ye et al. [54] findings suggesting that MWCNTs suppress osteoclastogenesis via the inhibition of osteoclast differentiation and induction of apoptosis in osteoclasts. Results also show that the addition of MWCNTs has a limited effect on RANKL expression at both day 60 and 120, indicating that MWCNTs are not the governing factor to trigger the osteoclast function. However, the use of ES seems to contribute to the osteoclast formation particularly after day 120 . Furthermore, ES seems to promote the RANKL expression and down-regulate the OPG expression at day 120, suggesting that the use of ES facilitates the bone resorption in the bone remodeling process. These results indicate that the combined use of conductive scaffolds and ES plays an important role in the bone remodeling process, providing cues that determine the osteoclast formation and function. In the future, we will further investigate the mechanism of ES modulating the bone remodeling process and optimize the ES processing conditions such as intensity, frequency and application time.

\section{Conclusion}

This work presents an in vivo study of 3D printed conductive PCL/MWCNT scaffolds with and without ES for bone tissue regeneration. Results show that the implantation of scaffolds, in particular the conductive PCL/MWCNT $3 \mathrm{wt} \%$ scaffold, into animal models contributes to thicker bone tissue formation within the bone defects. The combination of conductive PCL/MWCNTs scaffolds and ES can significantly promote the angiogenesis and lead to more mineralized bone tissue formation. Results also show that the implanted scaffolds contribute to the recruitment of TRAP positive cells (osteoclasts) and the addition of MWCNTs seems to inhibit the osteoclastogenesis. However, the use of ES is the dominant factor to activate TRAP positive cell's activities, promoting 
the osteoclast formation and the RANKL expression in the bone remodeling prevailing process. These results seem to indicate that the use of conductive PCL/MWCNTs and ES is a promising approach for bone tissue engineering and provides a cue to establish an optimal therapy to reach homeostasis.

Acknowledgements This project was financially supported by the University of Manchester/King Saud University research grant "Multi scale bioactive scaffolds for bone regeneration" project and the Engineering and Physical Sciences Research Council, the Global Challenges Research Fund (CRF), grant number EP/R01513/1; this project is also financially supported by University Center of Hermínio Ometto Foundation-FHO and CNPq ("Conselho Nacional do desenvolvimento Científico e Tecnológico”) grant number 423710/2018-4.

Author contributions EPS: Animal care and ethical procedures, Methodology, Results evaluation, Writing - original draft, Investigation; BH: Conceptualization, Writing - original draft, Investigation, Formal analysis, Visualization, Writing - review \& editing; JVH: Methodology, Results evaluation, Investigation. PRLN: Animal care and ethical procedures, Methodology, Investigation; LB: Animal care and ethical procedures, Methodology, Investigation, Results evaluation; MAO: Methodology, Investigation, Results evaluation; GCCA: in-vitro assay, Investigation, Results evaluation; AA: Writing - review \& editing, Funding acquisition; MEN: Writing - review \& editing, Funding acquisition; MSJr: Conceptualization, Animal care and ethical procedures, Methodology, Results evaluation, Writing - original draft, Formal analysis; FASM: Conceptualization, Formal analysis, Writing - original draft, Supervision; Project administration, Funding acquisition; PB: Conceptualization, Validation, Resources, Supervision, Project administration, Writing - review \& editing, Funding acquisition; GFC: Conceptualization, Methodology, Formal analysis, Writing - original draft, review \& editing, Supervision; Project administration, Funding acquisition.

\section{Compliance with ethical standards}

Conflict of interest There is no conflict of interest.

Ethical approval All institutional and national guidelines for the care and use of laboratory animals were followed.

Open Access This article is licensed under a Creative Commons Attribution 4.0 International License, which permits use, sharing, adaptation, distribution and reproduction in any medium or format, as long as you give appropriate credit to the original author(s) and the source, provide a link to the Creative Commons licence, and indicate if changes were made. The images or other third party material in this article are included in the article's Creative Commons licence, unless indicated otherwise in a credit line to the material. If material is not included in the article's Creative Commons licence and your intended use is not permitted by statutory regulation or exceeds the permitted use, you will need to obtain permission directly from the copyright holder. To view a copy of this licence, visit http://creativecomm ons.org/licenses/by/4.0/.

\section{References}

1. Minagawa T, Tabata Y, Oyama A, Furukawa H, Yamao T, Yamamoto Y (2014) Controlled release of granulocyte colonystimulating factor enhances osteoconductive and biodegradable properties of beta-tricalcium phosphate in a rat calvarial defect model. Int J Biomater 2014:134521. https://doi.org/10.1155/2014/ 134521

2. Oryan A, Alidadi S, Moshiri A, Maffulli N (2014) Bone regenerative medicine: classic options, novel strategies, and future directions. J Orthop Surg Res 9(1):18. https://doi.org/10.1186/1 749-799X-9-18

3. Caetano GF, Wang W, Chiang WH, Cooper G, Diver C, Blaker JJ, Frade MA, Bártolo P (2018) 3D printed poly (عcaprolactone)/graphene scaffolds activated with $\mathrm{p} 1$ latex protein for bone regeneration. 3D Print Additive Manuf 5(2):127-137. https:// doi.org/10.1089/3dp.2018.0012

4. Melchels FPW, Domingos MAN, Klein TJ, Malda J, Bartolo PJ, Hutmacher DW (2012) Additive manufacturing of tissues and organs. Prog Polym Sci 37(8):1079-1104. https://doi.org/10.101 6/j.progpolymsci.2011.11.007

5. Roseti L, Parisi V, Petretta M, Cavallo C, Desando G, Bartolotti I, Grigolo B (2017) Scaffolds for bone tissue engineering: state of the art and new perspectives. Mater Sci Eng, C 78:1246-1262. https:// doi.org/10.1016/j.msec.2017.05.017

6. Mata D, Horovistiz AL, Branco I, Ferro M, Ferreira NM, Belmonte M, Lopes MA, Silva RF, Oliveira FJ (2014) Carbon nanotube-based bioceramic grafts for electrotherapy of bone. Mater Sci Eng, C 34:360-368. https://doi.org/10.1016/j.msec.2013.09.028

7. Griffin M, Bayat A (2011) Electrical stimulation in bone healing: critical analysis by evaluating levels of evidence. Eplasty 11:e34-e34

8. Borgens RB (1984) Endogenous ionic currents traverse intact and damaged bone. Sci 225(4661):478. https://doi.org/10.1126/ science. 6740320

9. Gittens RA, Olivares-Navarrete R, Tannenbaum R, Boyan BD, Schwartz Z (2011) Electrical implications of corrosion for osseointegration of titanium implants. J Dent Res 90(12):1389-1397. https://doi.org/10.1177/0022034511408428

10. Vila M, Cicuéndez M, Sánchez-Marcos J, Fal-Miyar V, Manzano M, Prieto C, Vallet-Regi M (2013) Electrical stimuli to increase cell proliferation on carbon nanotubes/mesoporous silica composites for drug delivery. J Biomed Mater Res, Part A 101(1):213-221. https://doi.org/10.1002/jbm.a.34325

11. Thrivikraman G, Boda SK, Basu B (2018) Unraveling the mechanistic effects of electric field stimulation towards directing stem cell fate and function: a tissue engineering perspective. Biomater 150:60-86. https://doi.org/10.1016/j.biomaterials.2017.10.003

12. Wieding J, Lindner T, Bergschmidt P, Bader R (2015) Biomechanical stability of novel mechanically adapted open-porous titanium scaffolds in metatarsal bone defects of sheep. Biomater 46:35-47. https://doi.org/10.1016/j.biomaterials.2014.12.010

13. Bins-Ely LM, Cordero EB, Souza JCM, Teughels W, Benfatti CAM, Magini RS (2017) In vivo electrical application on titanium implants stimulating bone formation. J Periodontal Res 52(3):479-484. https://doi.org/10.1111/jre.12413

14. Ning C, Zhou Z, Tan G, Zhu Y, Mao C (2018) Electroactive polymers for tissue regeneration: developments and perspectives. Prog Polym Sci 81:144-162. https://doi.org/10.1016/j.progpolymsci.20 18.01.001

15. Hardy JG, Villancio-Wolter MK, Sukhavasi RC, Mouser DJ, Aguilar D Jr, Geissler SA, Kaplan DL, Schmidt CE (2015) Electrical stimulation of human mesenchymal stem cells on conductive nanofibers enhances their differentiation toward osteogenic outcomes. Macromol Rapid Commun 36(21):1884-1890. https://doi. org/10.1002/marc.201500233

16. Xu H, Holzwarth JM, Yan Y, Xu P, Zheng H, Yin Y, Li S, Ma PX (2014) Conductive PPY/PDLLA conduit for peripheral nerve regeneration. Biomater 35(1):225-235. https://doi.org/10.1016/j. biomaterials.2013.10.002 
17. Barroca N, Marote A, Vieira SI, Almeida A, Fernandes MHV, Vilarinho PM, daCruzSilva OAB (2018) Electrically polarized PLLA nanofibers as neural tissue engineering scaffolds with improved neuritogenesis. Coll Surf B: Biointerfaces 167:93-103. https://doi. org/10.1016/j.colsurfb.2018.03.050

18. Kopecká J, Kopecký D, Vrňata M, Fitl P, Stejskal J, Trchová M, Bober P, Morávková Z, Prokeš J, Sapurina I (2014) Polypyrrole nanotubes: mechanism of formation. RSC Adv 4(4):1551-1558. https://doi.org/10.1039/C3RA45841E

19. Wibowo A, Vyas C, Cooper G, Qulub F, Suratman R, Mahyuddin AI, Dirgantara T, Bartolo P (2020) 3D printing of polycaprolactone-polyaniline electroactive scaffolds for bone tissue engineering. Mater 13(3):512. https://doi.org/10.3390/ma13030512

20. Kayser LV, Lipomi DJ (2019) Stretchable conductive polymers and composites based on PEDOT and PEDOT:PSS. Adv Mater 31(10):1806133. https://doi.org/10.1002/adma.201806133

21. Ashtari K, Nazari H, Ko H, Tebon P, Akhshik M, Akbari M, Alhosseini SN, Mozafari M, Mehravi B, Soleimani M, Ardehali R, Ebrahimi Warkiani M, Ahadian S (2019) A khademhosseini electrically conductive nanomaterials for cardiac tissue engineering. Adv Drug Delivery Rev 144:162-179. https://doi.org/10.101 6/j.addr.2019.06.001

22. Hopley EL, Salmasi S, Kalaskar DM, Seifalian AM (2014) Carbon nanotubes leading the way forward in new generation 3D tissue engineering. Biotechnol Adv 32(5):1000-1014. https://doi.org/10. 1016/j.biotechadv.2014.05.003

23. Huang B, Vyas C, Roberts I, Poutrel Q-A, Chiang W-H, Blaker JJ, Huang Z, Bártolo P (2019) Fabrication and characterisation of 3D printed MWCNT composite porous scaffolds for bone regeneration. Mater Sci Eng, C 98:266-278. https://doi.org/10.1016/j. msec.2018.12.100

24. Huang B, Vyas C, Byun JJ, El-Newehy M, Huang Z, Bártolo $P$ (2020) Aligned multi-walled carbon nanotubes with nanohydroxyapatite in a $3 \mathrm{D}$ printed polycaprolactone scaffold stimulates osteogenic differentiation. Mater Sci Eng, C 108:110374. https:// doi.org/10.1016/j.msec.2019.110374

25. Cui H, Wang Y, Cui L, Zhang P, Wang X, Wei Y, Chen X (2014) In Vitro studies on regulation of osteogenic activities by electrical stimulus on biodegradable electroactive polyelectrolyte multilayers. Biomacromol 15(8):3146-3157. https://doi.org/10.1021/bm5 007695

26. Cui L, Zhang J, Zou J, Yang X, Guo H, Tian H, Zhang P, Wang Y, Zhang N, Zhuang X, Li Z, Ding J, Chen X (2020) Electroactive composite scaffold with locally expressed osteoinductive factor for synergistic bone repair upon electrical stimulation. Biomater 230:119617. https://doi.org/10.1016/j.biomaterials.2019.119617

27. Fani N, Hajinasrollah M, Asghari Vostikolaee MH, Baghaban Eslaminejad M, Mashhadiabbas F, Tongas N, Rasoulianboroujeni M, Yadegari A, Ede KF, Tahriri M, Tayebi L (2019) Influence of conductive PEDOT PSS in a hard tissue scaffold In vitro and in vivo study. J Bioactive Compatible Poly 34(6):436-441. https://doi.org/ $10.1177 / 0883911519881720$

28. Leppik L, Zhihua H, Mobini S, Thottakkattumana Parameswaran V, Eischen-Loges M, Slavici A, Helbing J, Pindur L, Oliveira KMC, Bhavsar MB, Hudak L, Henrich D, Barker JH (2018) Combining electrical stimulation and tissue engineering to treat large bone defects in a rat model. Sci Rep 8(1):6307. https://doi.org/10.1038/ s41598-018-24892-0

29. Fonseca Junior JH, Bagne L, Meneghetti DH, dos Santos GMT, Esquisatto MAM, de Andrade TAM, do Amaral MEC, Felonato M, Caetano GF, SantamariaJunior M, Mendonça FAS (2019) Electrical stimulation: complementary therapy to improve the performance of grafts in bone defects? J Biomed Mater Res Part B: Appl Biomater 107(4):924-932. https://doi.org/10.1002/jbm.b.34 187
30. Guex AG, Puetzer JL, Armgarth A, Littmann E, Stavrinidou E, Giannelis EP, Malliaras GG, Stevens MM (2017) Highly porous scaffolds of PEDOT:PSS for bone tissue engineering. Acta Biomater 62:91-101. https://doi.org/10.1016/j.actbio.2017.08.045

31. Chen J, Yu M, Guo B, Ma PX, Yin Z (2018) Conductive nanofibrous composite scaffolds based on in-situ formed polyaniline nanoparticle and polylactide for bone regeneration. J Colloid Interface Sci 514:517-527. https://doi.org/10.1016/j.jcis.2017.12.062

32. Huang Y, Deng H, Fan Y, Zheng L, Che J, Li X, Aifantis KE (2019) Conductive nanostructured Si biomaterials enhance osteogeneration through electrical stimulation. Mater Sci Eng, C 103:109748. https://doi.org/10.1016/j.msec.2019.109748

33. Maharjan B, Kaliannagounder VK, Jang SR, Awasthi GP, Bhattarai DP, Choukrani G, Park CH, Kim CS (2020) In-situ polymerized polypyrrole nanoparticles immobilized poly( $\varepsilon$-caprolactone) electrospun conductive scaffolds for bone tissue engineering. Mater Sci Eng C 114:111056. https://doi.org/10.1016/j.msec.2020.111056

34. Zhang J, Li M, Kang E-T, Neoh KG (2016) Electrical stimulation of adipose-derived mesenchymal stem cells in conductive scaffolds and the roles of voltage-gated ion channels. Acta Biomater 32:46-56. https://doi.org/10.1016/j.actbio.2015.12.024

35. Khatib L, Golan DE, Cho M (2004) Physiologic electrical stimulation provokes intracellular calcium increase mediated by phospholipase $\mathrm{C}$ activation in human osteoblasts. FASEB J Off Publ Fed Am Soc Exp Biol 18(15):1903-1905. https://doi.org/10.1096/fj.0 4-1814fje

36. Leppik L, Oliveira KMC, Bhavsar MB, Barker JH (2020) Electrical stimulation in bone tissue engineering treatments. Eur J Trauma Emerg Surg 46(2):231-244. https://doi.org/10.1007/s00068-020-0 1324-1

37. Spadari GS, Zaniboni E, Vedovello SAS, Santamaria MP, do Amaral MEC, dosSantos GMT, Esquisatto MAM, Mendonca FAS, Santamaria-Jr M(2017) Electrical stimulation enhances tissue reorganization during orthodontic tooth movement in rats. Clin oral invest 21(1):111-120. https://doi.org/10.1007/s00784-016-1759-6

38. Maes C (2013) Role and regulation of vascularization processes in endochondral bones. Calcif Tissue Int 92(4):307-323. https://doi. org/10.1007/s00223-012-9689-z

39. Schipani E, Maes C, Carmeliet G, Semenza GL (2009) Regulation of osteogenesis-angiogenesis coupling by hifs and VEGF. J Bone Miner Res 24(8):1347-1353. https://doi.org/10.1359/jbmr.090602

40. Kim IS, Song JK, Zhang YL, Lee TH, Cho TH, Song YM, Kim DK, Kim SJ, Hwang SJ (2006) Biphasic electric current stimulates proliferation and induces VEGF production in osteoblasts. Biochim Biophy Acta (BBA) Mol Cell Res 1763(9):907—916. https://doi. org/10.1016/j.bbamcr.2006.06.007

41. Zhao M, Bai H, Wang E, Forrester JV, McCaig CD (2004) Electrical stimulation directly induces pre-angiogenic responses in vascular endothelial cells by signaling through VEGF receptors. J Cell Sci 117(3):397. https://doi.org/10.1242/jcs.00868

42. Haniu H, Saito N, Matsuda Y, Tsukahara T, Maruyama K, Usui Y, Aoki K, Takanashi S, Kobayashi S, Nomura H, Okamoto M, Shimizu M, Kato H (2013) Culture medium type affects endocytosis of multi-walled carbon nanotubes in BEAS-2B cells and subsequent biological response. Toxicol In Vitro 27(6):1679-1685. https://doi.org/10.1016/j.tiv.2013.04.012

43. Mukherjee S, Nandi SK, Kundu B, Chanda A, Sen S, Das PK (2016) Enhanced bone regeneration with carbon nanotube reinforced hydroxyapatite in animal model. J Mech Behav Biomed Mater 60:243-255. https://doi.org/10.1016/j.jmbbm.2016.02.005

44. Liu X, George MN, Park S, Miller Ii AL, Gaihre B, Li L, Waletzki BE, Terzic A, Yaszemski MJ, Lu L (2020) 3D-printed scaffolds with carbon nanotubes for bone tissue engineering: fast and homogeneous one-step functionalization. Acta Biomater 111:129. https://doi.org/10.1016/j.actbio.2020.04.047 
45. Liao S, Xu G, Wang W, Watari F, Cui F, Ramakrishna S, Chan CK (2007) Self-assembly of nano-hydroxyapatite on multi-walled carbon nanotubes. Acta Biomater 3(5):669-675. https://doi.org/1 0.1016/j.actbio.2007.03.007

46. Nardecchia S, Serrano MC, Gutiérrez MC, Portolés MT, Ferrer ML, del Monte F (2012) Osteoconductive performance of carbon nanotube scaffolds homogeneously mineralized by flow-through electrodeposition. Adv Func Mater 22(21):4411-4420. https://doi. org/10.1002/adfm.201200684

47. Boyce B, Yao Z, Xing L (2009) Osteoclasts have multiple roles in bone in addition to bone resorption. Crit Rev in Eukaryot Gene Expr 19(3):171-180. https://doi.org/10.1615/ CritRevEukarGeneExpr.v19.i3.10

48. Vega D, Maalouf NM, Sakhaee K (2007) The role of receptor activator of nuclear factor- $\mathrm{kB}$ (RANK)/RANK ligand/osteoprotegerin: clinical implications. J Clin Endocrinol Metab 92(12):4514-4521. https://doi.org/10.1210/jc.2007-0646

49. Lotz EM, Berger MB, Schwartz Z, Boyan BD (2018) Regulation of osteoclasts by osteoblast lineage cells depends on titanium implant surface properties. Acta Biomater 68:296-30. https://doi.org/10.1 016/j.actbio.2017.12.039

50. Niu H, Ma Y, Wu G, Duan B, Wang Y, Yuan Y, Liu C (2019) Multicellularity-interweaved bone regeneration of BMP-2-loaded scaffold with orchestrated kinetics of resorption and osteogenesis. Biomater 216:119216. https://doi.org/10.1016/j.biomaterials.2 019.05.027
51. Helmrich U, Di Maggio N, Güven S, Groppa E, Melly L, Largo RD, Heberer M, Martin I, Scherberich A, Banfi A (2013) Osteogenic graft vascularization and bone resorption by VEGF-expressing human mesenchymal progenitors. Biomater 34(21):5025-5035. https://doi.org/10.1016/j.biomaterials.2013.03.040

52. Kim HD, Jang HL, Ahn H-Y, Lee HK, Park J, Lee E-S, Lee EA, Jeong Y-H, Kim D-G, Nam KT, Hwang NS (2017) Biomimetic whitlockite inorganic nanoparticles-mediated in situ remodeling and rapid bone regeneration. Biomater 112:31-43. https://doi.org/ 10.1016/j.biomaterials.2016.10.009

53. Liu W, Dan X, Lu WW, Zhao X, Ruan C, Wang T, Cui X, Zhai X, Ma Y, Wang D, Huang W, Pan H (2019) Spatial distribution of biomaterial microenvironment ph and its modulatory effect on osteoclasts at the early stage of bone defect regeneration. ACS Appl Mater Interfaces 11(9):9557-9572. https://doi.org/10.1021/ acsami.8b20580

54. Li Y, Li F, Zhang C, Gao B, Tan P, Mi B, Zhang Y, Cheng H, Liao H, Huo K, Xiong W (2015) The dimension of titania nanotubes influences implant success for osteoclastogenesis and osteogenesis patients. J Nanosci Nanotechnol 15(6):4136-4142. https://doi.org/ 10.1166/jnn.2015.9602 